\title{
Reduced prefrontal hemodynamic response in pediatric autism spectrum disorder measured with near-infrared spectroscopy
}

\author{
Mitsuhiro Uratani ${ }^{1}$, Toyosaku Ota ${ }^{2 *}$, Junzo lida ${ }^{3}$, Kosuke Okazaki $^{2}$, Kazuhiko Yamamuro ${ }^{2}$, Yoko Nakanishi ${ }^{2}$, \\ Naoko Kishimoto ${ }^{2}$ and Toshifumi Kishimoto ${ }^{2}$
}

\begin{abstract}
Background: Functional neuroimaging studies suggest that prefrontal cortex dysfunction is present in people with autism spectrum disorder (ASD). Near-infrared spectroscopy is a noninvasive optical tool for examining oxygenation and hemodynamic changes in the cerebral cortex by measuring changes in oxygenated hemoglobin.
\end{abstract}

Methods: Twelve drug-naïve male participants, aged 7-15 years and diagnosed with ASD according to DSM- 5 criteria, and 12 age- and intelligence quotient (IQ)-matched healthy control males participated in the present study after giving informed consent. Relative concentrations of oxyhemoglobin were measured with frontal probes every $0.1 \mathrm{~s}$ during the Stroop color-word task, using 24-channel near-infrared spectroscopy.

Results: Oxyhemoglobin changes during the Stroop color-word task in the ASD group were significantly smaller than those in the control group at channels 12 and 13, located over the dorsolateral prefrontal cortex (FDR-corrected P: 0.0021-0.0063).

Conclusion: The results suggest that male children with ASD have reduced prefrontal hemodynamic responses, measured with near-infrared spectroscopy.

Keywords: Pediatric autism spectrum disorder, Near-infrared spectroscopy, Prefrontal hemodynamic response, Attention, Executive function

\section{Background}

Autism spectrum disorder (ASD) is a neurodevelopmental disorder, characterized by impairments in social and communicative functioning and the presence of restricted interests and repetitive behaviors [1]. Studies using neuropsychological measures have revealed an association between ASD and inattention. ASD can be characterized by a short attention span, and impulsivity and inattention symptoms are common [2]. Furthermore, individuals with ASD are typically impaired on neurocognitive measures of sustained and selective attention [3]. There is evidence for fronto-striatal, parietal, and

\footnotetext{
*Correspondence: toyosaku@naramed-u.ac.jp

2 Department of Psychiatry, Nara Medical University, 840 Shijyo-cho,

Kashihara, Nara 634-8522, Japan

Full list of author information is available at the end of the article
}

cerebellar abnormalities in ASD during selective and flexible attention $[4,5]$. In addition to attentional difficulties, many studies have indicated that individuals with ASD exhibit impairments of executive function $[6,7]$. A wealth of data indicates that the prefrontal cortex plays a major role in executive function.

Multi-channel near-infrared spectroscopy (NIRS) enables the noninvasive detection of neural activity near the surface of the brain using near-infrared light $[8,9]$. NIRS measures alterations in oxygenated hemoglobin (oxy- $\mathrm{Hb}$ ) and deoxygenated hemoglobin (deoxy-Hb) concentrations in micro-blood vessels on the brain surface. Local increases in the concentration of oxy- $\mathrm{Hb}$ and decreases in the concentration of deoxy- $\mathrm{Hb}$ are indicators of cortical activity $[8,10]$. In addition, changes in the concentration of oxy-Hb have been associated with changes in regional cerebral blood volume, using a combination of 
positron emission tomography (PET) and NIRS measurements [11, 12]. NIRS is a neuroimaging modality that, according to Matsuo et al. [13], is especially suitable for psychiatric patients for the following reasons. First, because NIRS is relatively insensitive to motion artifacts, it can be used in experiments where motion is expected, such as those involving vocalization. Second, NIRS can be used to examine participants while seated in a natural position, with minimal environmental distraction. Third, NIRS has cheaper running costs than other neuroimaging modalities and is simple to set up and use. Fourth, the high temporal resolution of NIRS is useful for characterizing the time course of prefrontal activity in people with psychiatric disorders [14, 15]. Accordingly, NIRS has been used to assess brain function in people with many psychiatric disorders, including schizophrenia, bipolar disorder, depression, obsessive-compulsive disorder, dementia, post traumatic stress disorder, Tourette's disorder, attention-deficit/hyperactivity disorder, and ASD [13-27].

Recent developments in NIRS have enabled noninvasive clarification of brain functions in pediatric psychiatric disorders. In pediatric ASD, reduced prefrontal hemodynamic activity has been reported in studies using NIRS measurement during self-face recognition and auditory tasks [28, 29]. Yasumura et al. [30] reported no significant differences in prefrontal hemodynamic activity between typically developing and ASD children (seven boys and four girls) measured with NIRS during the Stroop task. Similarly, Xiao et al. [31] reported no significant differences in prefrontal hemodynamic activity between typically developing controls and boys with ASD measured with 16-channel NIRS during the Stroop task. However, it is difficult to accurately measure the dorsolateral prefrontal hemodynamic activity using 16-channel NIRS, which is more suitable for measuring hemodynamic responses of the orbitofrontal and frontopolar cortex. The Stroop color-word task is one of the most commonly used methods for identifying attentional problems, as well as providing a test of executive function, and involves the dorsolateral prefrontal cortex. Moreover, sex differences in executive function in people with ASD have been reported in children and adolescents [32-34]. Therefore, it may be valuable to examine the broader prefrontal hemodynamic response in male children with ASD, measured with 24-channel NIRS during the Stroop color-word task. We hypothesized that male children with ASD would exhibit reduced prefrontal hemodynamic responses in 24-channel NIRS during the Stroop color-word task. Thus, in the present study, we used 24-channel NIRS to examine the characteristics of prefrontal cerebral blood volume changes during the Stroop color-word task in male children with ASD and in age- and intelligence quotient (IQ)-matched healthy control males.

\section{Methods \\ Participants}

Twelve drug-naïve male participants, aged 7-15 years, and diagnosed with ASD according to DSM-5 criteria [1], were compared with 12 age- and IQ-matched healthy control males, aged 6-12 years (Table 1).

Participants were individuals with ASD who had no history of previous psychiatric disorder treatment, and had consulted one of the experienced pediatric psychiatrists at the Department of Psychiatry of Nara Medical University that anyone with demand could visit at any time without constraints of severity, age, residence, economics, and so on. Participants with ASD underwent a standard clinical assessment comprising a psychiatric evaluation, a semi-structured interview system for ASD (the Pervasive Developmental Disorders Assessment System) [35], and an examination of medical history by an experienced pediatric psychiatrist. Two experienced pediatric psychiatrists confirmed the diagnosis of ASD in accordance with the DSM-5. Participants' intellectual level was assessed using the Wechsler Intelligence Scale for Children-Fourth Edition by the psychologist, and individuals with full-scale IQ (FIQ) scores below 70 were excluded. Patients who presented with a comorbid psychiatric disorder defined by the DSM-5, a neurological disorder, a head injury, a serious medical condition, or a history of substance abuse/dependence were excluded; two patients with attention-deficit/hyperactivity disorder and two patients with persistent motor tic disorder were excluded. Finally, 12 participants with ASD, who had no previous medication history, were enrolled in the present study. Of 12 participants, two had been previously

Table 1 Participants' characteristics

\begin{tabular}{lcll}
\hline & \multicolumn{1}{l}{$\begin{array}{l}\text { ASD } \\
\text { Mean (SD) }\end{array}$} & $\begin{array}{l}\text { Control } \\
\text { Mean (SD) }\end{array}$ & P value \\
\hline Number (sex ratio: M:F) & $12(12: 0)$ & $12(12: 0)$ & \\
Age (years) & $9.75(2.26)$ & $9.50(2.20)$ & 0.79 \\
First diagnosed age (years) & $8.17(1.95)$ & NA & \\
FIQ (WISC-IV) & $100.92(15.72)$ & $97.83(7.66)$ & 0.55 \\
SCWC-1 & $34.58(12.32)$ & $38.58(7.13)$ & 0.34 \\
SCWC-2 & $36.92(10.47)$ & $38.58(7.96)$ & 0.67 \\
SCWC-3 & $35.42(11.98)$ & $37.08(9.10)$ & 0.71 \\
\hline
\end{tabular}

Group differences tested with $t$-test

ASD autism spectrum disorder, $M$ male, $F$ female, FIQ (WISC-IV) Full-scale IQ score of the Wechsler Intelligence Scale for Children-Fourth Edition, SCWC-1 Stroop color-word task number of correct answers first time, SCWC-2 Stroop color-word task number of correct answers second time, SCWC-3 Stroop color-word task number of correct answers third time 
diagnosed by the pediatric neurologist at the other hospital, three had been previously diagnosed by using the Autism Diagnostic Interview Revised, one had been previously diagnosed by using the Autism Diagnostic Observation Schedule, and other participants were diagnosed for the first time at the Department of Psychiatry of Nara Medical University.

Healthy control participants were recruited from local elementary schools and junior high schools. They also underwent a standard clinical assessment comprising a psychiatric evaluation, a standard diagnostic interview (Structured Clinical Interview for DSM-IV-TR Axis I Disorders Non-Patient Edition), and an examination of medical history by an experienced pediatric psychiatrist. Participants' intellectual level was assessed using the Wechsler Intelligence Scale for Children-Fourth Edition by the psychologist. Finally, 12 healthy control participants, who did not have confirmed ASD and who had no current or past history of psychiatric or neurological disorders, were also enrolled in the present study.

All participants were able to read the Japanese syllabary characters called hiragana, right-handed and Japanese. All participants and/or their parents provided written informed consent for their participation in the study. We informed our patients about this study on their initial visit and enrolled them as the participant of this study in order of consent. This study was approved by the Institutional Review Board at the Nara Medical University (approval number 325-2).

\section{The Stroop color-word task}

The traditional Stroop task involves a word-reading task, an incongruent color naming task, and a color naming task. We reconstructed the Stroop task according to previously described methods [36]. The Stroop colorword task consisted of two pages: each page contained 100 items in five columns of 20 items each and the page size was $210 \times 297 \mathrm{~mm}$. On the first page, the words RED, GREEN, and BLUE were printed in black ink. On the second page, the words RED, GREEN, and BLUE were printed in red, green, or blue ink, with the limitation that the word meaning and ink color never matched. The items on both pages were randomly distributed, with the exception that no item could appear directly after the same item within a column.

Before the task, the examiners gave the participants the following instructions: "This task is to test how quickly you can read the words on the first page, and say the colors of the words on the second page. After we say 'begin', please read the words in the columns, starting at the top left, and say the words/colors as quickly as you can. After you finish reading the words in the first column, go on to the next column, and so on. After you have read the words on the first page for $45 \mathrm{~s}$, we will turn the page. Please repeat this procedure for the second page."

The entire Stroop color-word task sequence consisted of three cycles of 45-s spent reading the first page, 45-s spent reading the second page (the color-word task). The task ended with 45-s spent reading the first page, which we designated as the baseline task (Fig. 1c). We recorded the number of correct answers in each cycle, and refer to them as follows: Stroop color-word task number of correct answers first time (SCWC-1), second time (SCWC2), and third time (SCWC-3). Examiners who were blind to the participants' diagnoses administered the Stroop color-word task.

Importantly, the Stroop task used in this study was different to the traditional Stroop task. We used a simplified version of the Stroop color-word task because the participants were school-age children. In addition, we excluded the color-naming task (part of the traditional Stroop task) because we needed only two tasks (baseline task and activation task) for our NIRS study.

The Stroop color-word task was utilized for the following reasons. First, the inferior frontal gyrus is reported to be one of the regions most strongly related to Stroop interference [37]. Second, in the NIRS study that the same task was used, Negoro et al. [26] concluded that suitable prefrontal brain activation in healthy children was recognized by using the Stroop color-word task.

\section{NIRS measurements}

Increased oxy- $\mathrm{Hb}$ and decreased deoxy- $\mathrm{Hb}$, measured with NIRS, have been reported to reflect cortical activation. In animal studies, oxy- $\mathrm{Hb}$ is the most sensitive indicator of regional cerebral blood flow because the direction of change in deoxy-Hb is determined by the degree of change in venous blood oxygenation and volume [38]. Therefore, we focused on changes in oxy- $\mathrm{Hb}$. We measured oxy-Hb using a 24-channel NIRS machine (Hitachi ETG-4000, Hitachi Medical Corporation, Tokyo, Japan). We measured the absorption of two wavelengths of near-infrared light (760 and $840 \mathrm{~nm})$. We analyzed the optical data based on the modified Beer-Lambert Law [39] as previously described [40]. This method enabled us to calculate signals reflecting oxy- $\mathrm{Hb}$, deoxy- $\mathrm{Hb}$, and total-Hb signal changes. The scale of the hemoglobin quantity is $\mathrm{mmol} \times \mathrm{mm}$, meaning that all concentration changes depend on the path length of the near-infrared light. The recording channels were located over the optical path in the brain between neighboring pairs of emitters and detectors (Fig. 1a). The inter-probe intervals of the system were $3.0 \mathrm{~cm}$, and previous reports have established that the device measures activity at a point $2-3 \mathrm{~cm}$ beneath the scalp (i.e., the surface of the cerebral cortex) $[19,41]$. 
a

\begin{tabular}{|c|c|c|c|c|c|c|}
\hline [] & (1) & 11 & (2) & 12 & (3) & 12 \\
\hline (4) & & () & & (6) & & (7) \\
\hline 13 & (8) & 13 & (9) & 14 & (10) & 14 \\
\hline (11) & & (12) & & (13) & & (14) \\
\hline 15 & (15) & 15 & (16) & 16 & (17) & 16 \\
\hline (18) & & (19) & & (20) & & (21) \\
\hline 17 & (22) & 17 & (23) & 18 & (24) & 18 \\
\hline
\end{tabular}

Emitter

$\bigcirc$ Channel b

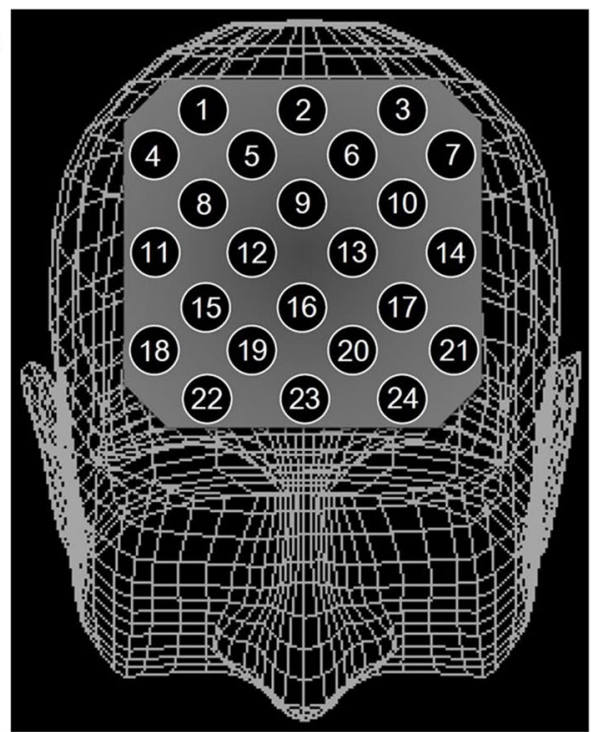

C

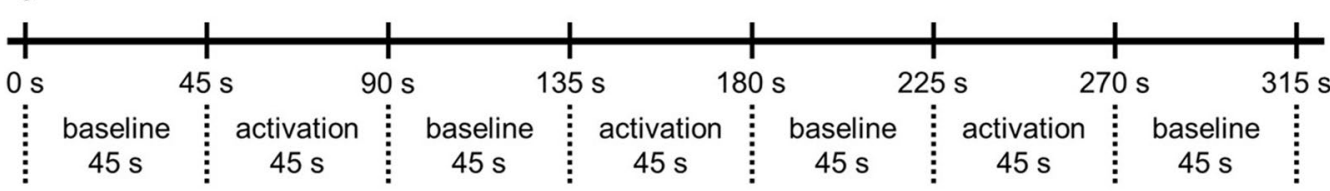

baseline task

あか (RED) みどり (GREEN) あお (BLUE)

activation task

あか (BLUE) みどり (RED) あお (GREEN)

Fig. 1 Location of the 24 channels of the near-infrared spectroscopy device. a Arrangement of emitters and detectors according to the definition of each channel. $\mathbf{b}$ Corresponding anatomical site of each channel. c Timeline of stimulus presentation. The baseline task is the word reading task. The activation condition is the incongruent color naming task

The participants maintained a natural sitting position during NIRS measurements. The distance between the eyes of each participant and the paper on which the items were listed was set to between $30 \mathrm{~cm}$ and $40 \mathrm{~cm}$. The NIRS probes were placed on the scalp over the prefrontal brain regions, and arranged to measure the relative changes in $\mathrm{Hb}$ concentration at 24 measurement points that made up an $8 \times 8 \mathrm{~cm}$ square (Fig. 1a). The lowest probes were positioned along the Fp1-Fp2 line, according to the international $10 / 20$ system commonly used in electroencephalography. The probe positions and measurement points on the cerebral cortex were confirmed by overlaying the probe positions on a three-dimensionally reconstructed magnetic resonance imaging scan of the cerebral cortex of a representative participant from the control group (Fig. 1b). The absorption of near-infrared light was measured with a time resolution of $0.1 \mathrm{~s}$. The data were analyzed using the "integral mode": the pretask line was determined as the mean across the $10 \mathrm{~s}$ just before the task period; the post-task line was determined as the mean across the $25 \mathrm{~s}$ immediately after the task period; using two lines, the baseline was drawn using the least-squares method; the three oxy-Hb changes of the activation task were then averaged. The moving average method was used to exclude short-term motion artifacts in the analyzed data (moving average window, $5 \mathrm{~s}$ ).

We attempted to exclude motion artifacts by closely monitoring artifact-evoking body movements, such as neck movements, biting, and blinking (identified as the most influential in a preliminary artifact-evoking study), and by instructing the participants to avoid these movements during the NIRS measurements. Examiners were blind to the participants' diagnoses.

\section{Statistical analyses}

We used Student's $t$-tests to compare oxy-Hb changes between the two groups by calculating the grand average waveforms every $0.1 \mathrm{~s}$ in each channel. This 
analysis enabled more detailed comparison of oxy$\mathrm{Hb}$ changes along the time course of the task. Data analyses were conducted using MATLAB 6.5.2 (Mathworks, Natick, MA, USA) and Topo Signal Processing type-G version 2.05 (Hitachi Medical Corporation, Tokyo, Japan). OT-A4 version $1.63 \mathrm{~K}$ (Hitachi Medical
Corporation, Tokyo, Japan) was used for the overlap display of the grand average waveforms in both groups in Fig. 2 and was also used to calculate mean oxy- $\mathrm{Hb}$ measurements in Table 2. Because we performed 24 paired $t$-tests, correction for multiple comparisons was conducted using the false discovery rate (FDR)

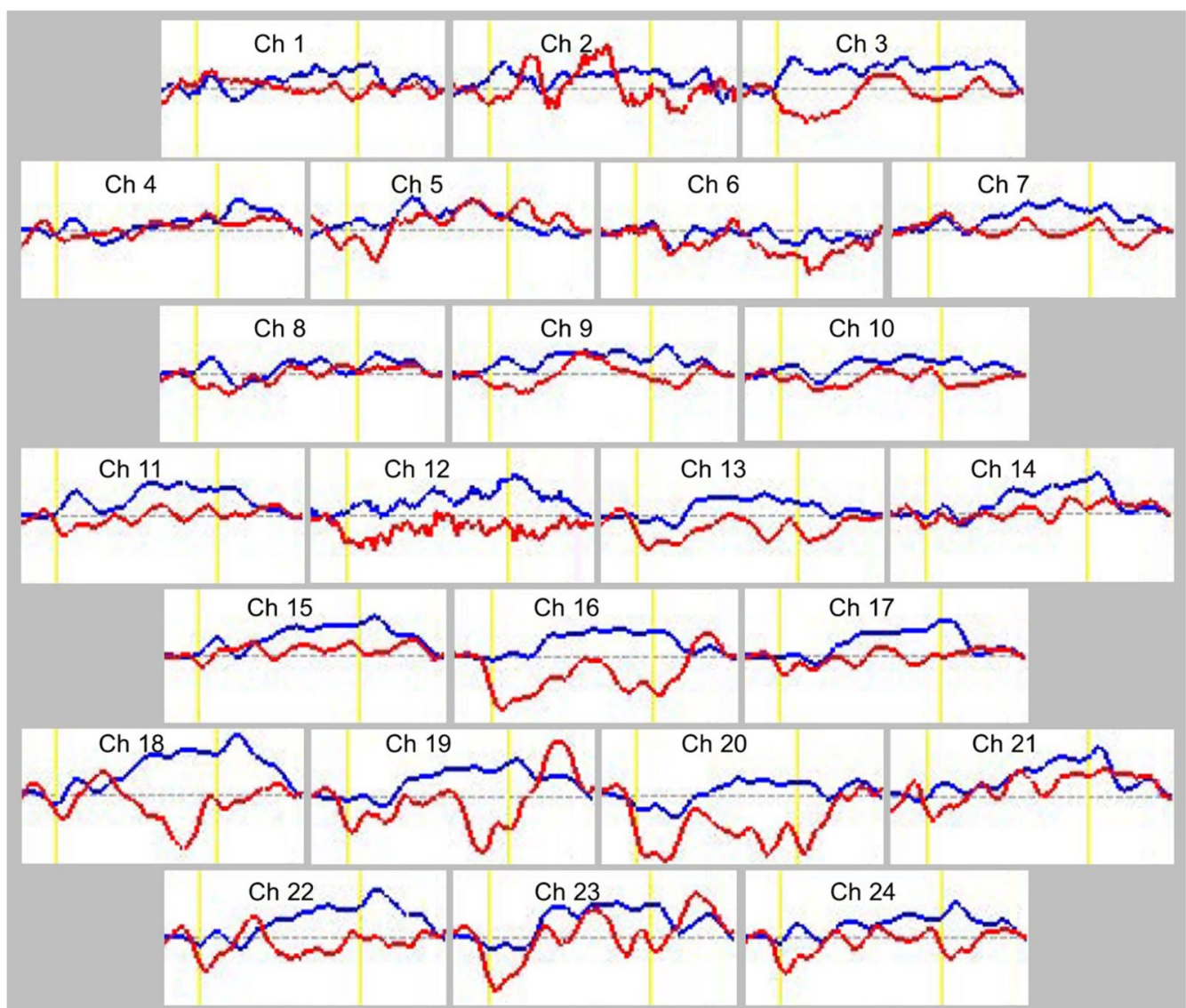

Fig. 2 Grand average waveforms of oxyhemoglobin (oxy-Hb) concentration changes during the Stroop color-word task in both groups. The red lines are the grand average waveforms of oxy- $\mathrm{Hb}$ in the autism spectrum disorder (ASD) group, and the blue lines are the grand average waveforms of oxy-Hb in the control group. The activation task was performed in the time period between the yellow lines

Table 2 Correlations between Stroop task and participants' characteristics

\begin{tabular}{|c|c|c|c|c|c|c|}
\hline & ASD & & & Control & & \\
\hline & SCWC-1 & SCWC-2 & SCWC-3 & SCWC-1 & SCWC-2 & SCWC-3 \\
\hline Age & $0.790^{*}$ & $0.582^{*}$ & $0.618^{*}$ & $0.577^{*}$ & $0.576^{*}$ & $0.598^{*}$ \\
\hline FIQ (WISC-IV) & -0.165 & -0.187 & -0.240 & -0.272 & -0.279 & -0.290 \\
\hline
\end{tabular}

Correlations between Stroop task and participants' characteristics tested with Spearman's correlation test

ASD autism spectrum disorder, FIQ (WISC-IV) Full-scale IQ score of the Wechsler Intelligence Scale for Children-Fourth Edition, SCWC-1 Stroop color-word task number of correct answers first time, SCWC-2 Stroop color-word task number of correct answers second time, SCWC-3 Stroop color-word task number of correct answers third time

${ }^{*} \mathrm{P}<0.05$

** $\mathrm{P}<0.01$ 
(two-tailed; we set the value of $q$ specifying the maximum FDR to 0.05 , so that there are no more than $5 \%$ false positives on average) [42]. PASW Statistics $18.0 \mathrm{~J}$ for Windows (SPSS, Tokyo, Japan) was used for statistical analysis.

\section{Results}

\section{Demographic data}

Demographic and clinical data are shown in Table 1. Age and FIQ did not differ significantly across patients with ASD and healthy controls $(\mathrm{t}=0.28, d f=22$, $\mathrm{P}=0.79 ; \mathrm{t}=0.61, d f=22, \mathrm{P}=0.55)$. There were no significant differences in the SCWC-1, SCWC-2, and SCWC-3 scores between the two groups $(t=-0.97$, $d f=22, \quad \mathrm{P}=0.34 ; \quad \mathrm{t}=-0.44, \quad d f=22, \quad \mathrm{P}=0.67 ;$ $\mathrm{t}=-0.38, d f=22, \mathrm{P}=0.71$ ).

\section{Correlation between the Stroop task and characteristics} of the participants

Spearman's $\rho$ correlations between SCWC scores and age, and FIQ scores are shown in Table 2. In both groups, the results revealed positive correlations between SCWC scores and age, and no correlations between SCWC scores and FIQ.

\section{NIRS data during the stroop color-word task}

The grand average waveforms of oxy- $\mathrm{Hb}$ concentration changes during the Stroop color-word task in both groups can be seen in Fig. 2. The grand average waveforms of the oxy- $\mathrm{Hb}$ concentration change in the control group increased during the task period, whereas those in the ASD group did not show substantial changes. The difference in mean oxy- $\mathrm{Hb}$ measurements between the task and post-task periods in 24-channels NIRS is shown in Table 3. Between the task and post-task periods, the

Table 3 Difference of mean oxyhemoglobin (oxy-Hb) measurements between task and post-task periods in 24 channels

\begin{tabular}{|c|c|c|c|c|c|c|}
\hline & ASD (mM & & Control ( & & Student's t-test & FDR correction \\
\hline & Mean & SD & Mean & SD & & \\
\hline Ch 1 & 0.0049 & 0.0658 & 0.0210 & 0.0447 & NS & NS \\
\hline Ch 2 & 0.0055 & 0.0511 & 0.0267 & 0.0653 & NS & NS \\
\hline Ch 3 & -0.0161 & 0.0987 & 0.0427 & 0.0444 & $\dagger$ & NS \\
\hline Ch 4 & 0.0085 & 0.0470 & 0.0146 & 0.0423 & NS & NS \\
\hline Ch 5 & 0.0203 & 0.0728 & 0.0239 & 0.0414 & NS & NS \\
\hline Ch 6 & -0.0323 & 0.0586 & -0.0087 & 0.0329 & NS & NS \\
\hline Ch 7 & -0.0003 & 0.0483 & 0.0301 & 0.0454 & NS & NS \\
\hline Ch 8 & -0.0014 & 0.0560 & 0.0257 & 0.0498 & NS & NS \\
\hline Ch 9 & -0.0016 & 0.0515 & 0.0312 & 0.0307 & $\dagger$ & NS \\
\hline Ch 10 & -0.0121 & 0.0576 & 0.0288 & 0.0451 & $\dagger$ & NS \\
\hline Ch 11 & -0.0005 & 0.0489 & 0.0349 & 0.0345 & $\dagger$ & NS \\
\hline Ch 12 & -0.0299 & 0.0567 & 0.0396 & 0.0358 & $* *$ & $* * *$ \\
\hline Ch 13 & -0.0317 & 0.0483 & 0.0255 & 0.0352 & $* *$ & $* * *$ \\
\hline Ch 14 & 0.0058 & 0.0814 & 0.0334 & 0.0167 & NS & NS \\
\hline Ch 15 & 0.0134 & 0.0705 & 0.0438 & 0.0271 & NS & NS \\
\hline Ch 16 & -0.0420 & 0.0469 & 0.0306 & 0.0198 & NS & NS \\
\hline Ch 17 & -0.0037 & 0.0680 & 0.0298 & 0.0188 & NS & NS \\
\hline Ch 18 & -0.0189 & 0.0712 & 0.0651 & 0.0462 & $* *$ & NS \\
\hline Ch 19 & -0.0145 & 0.1062 & 0.0327 & 0.0460 & NS & NS \\
\hline Ch 20 & -0.0718 & 0.1045 & 0.0005 & 0.0471 & * & NS \\
\hline Ch 21 & 0.0239 & 0.0805 & 0.0480 & 0.0318 & NS & NS \\
\hline Ch 22 & -0.0144 & 0.0544 & 0.0328 & 0.0578 & $\dagger$ & NS \\
\hline Ch 23 & 0.0028 & 0.1099 & 0.0381 & 0.0507 & NS & NS \\
\hline Ch 24 & -0.0106 & 0.0858 & 0.0318 & 0.0345 & NS & NS \\
\hline
\end{tabular}

Group differences tested with $t$-test and false discovery rate (FDR) correction

* $\mathrm{P}<0.05$

** $\mathrm{P}<0.01$

*** $\mathrm{P}<$ FDR-corrected $\mathrm{P}$

$+\mathrm{P}<0.1$ 
mean oxy-Hb difference of the ASD group was significantly smaller than that of the control group in channels 12 and 13 (FDR-corrected P: 0.0021 to 0.0042). A topographic representation of the $\mathrm{t}$-values of oxy-Hb comparison between the ASD group and the control group during the Stroop color-word task is shown in Fig. 3. The oxy- $\mathrm{Hb}$ changes in the control group were significantly greater than with those in the ASD group during the task period in the prefrontal cortex.

\section{Discussion}

To the best of our knowledge, no previous studies have examined the broader prefrontal hemodynamic response in male children with ASD, measured with 24-channel NIRS during the Stroop color-word task. In the present study, the results revealed that oxy$\mathrm{Hb}$ changes in 12 drug-naïve male children with ASD during the Stroop color-word task were significantly smaller than those in 12 healthy male children in the prefrontal cortex, particularly in the dorsolateral prefrontal cortex (Ch 12 and Ch 13). The present findings supported our hypothesis, in accord with the proposed prefrontal dysfunction in pediatric ASD identified by other imaging modalities, such as functional magnetic resonance imaging (fMRI) and single-photon emission computed tomography (SPECT). Previous SPECT studies reported localized areas of hypoperfusion, which may be correlated with focal reductions in function observed in the prefrontal lobes, cingulate gyrus, superior temporal gyrus, and mesial temporal lobes of individuals with ASD [43]. In ASD, fMRI studies of motor and cognitive interference inhibition and switching reported abnormalities in fronto-striato-parietal areas, including dorsolateral prefrontal cortex and ventrolateral prefrontal cortex [44, 45].

At Ch 12 and Ch 13, male children with ASD were associated with significantly smaller oxy-Hb changes than healthy children in the present study. Those channels were localized in the dorsolateral prefrontal cortex, whose hypoactivation was observed in ASD during cognitive control tasks involving inhibition [46], attention $[47,48]$, and working memory $[49,50]$. Two previous studies used 16-channel NIRS during the Stroop task in ASD [30, 31]. However, accurately measuring dorsolateral prefrontal hemodynamic activity is difficult with 16-channel NIRS, which is more suitable for measuring the hemodynamic response of the orbitofrontal and frontopolar cortices. Thus, no significant differences were found between ASD children and typically developing controls in prefrontal hemodynamic activity measured with 16-channel NIRS during the Stroop task. In the current study, we used a 24-channel NIRS system rather than a 16-channel system. The results revealed that male children with ASD exhibited reduced dorsolateral prefrontal

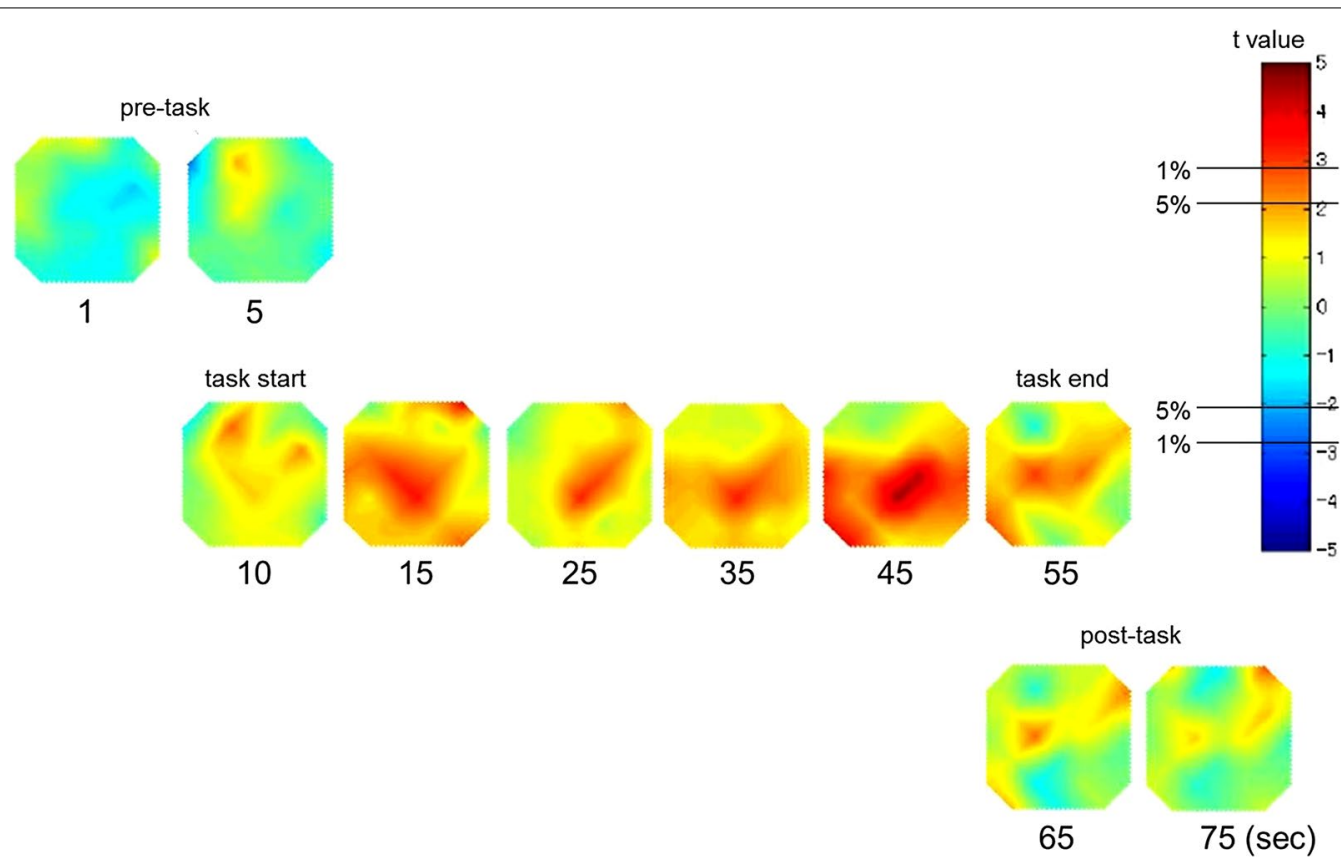

Fig. 3 Topographic presentation of the $t$ value of the oxyhemoglobin (oxy-Hb) comparison between the control group and the autism spectrum disorder (ASD) group during the Stroop color-word task. The $t$ values of oxy-Hb for the control and ASD groups are presented as a topographic map along the time course of the task (from top to bottom). The red, green, and blue areas in the topographs indicate positive, zero, and negative $t$ values, with \pm 2.8 and \pm 2.1 for the $1 \%$ and $5 \%$ statistical significance levels, respectively 
hemodynamic responses, measured with 24-channel NIRS during the Stroop color-word task.

In the present study, we used the Stroop color-word task because the prefrontal cortex is reported to be one of the regions most strongly related to Stroop interference [37]. Negoro et al. [26] examined brain activation in 20 healthy children during the Stroop color-word task, measured with NIRS. In that study, oxy-Hb changes indicated specific activation in the prefrontal cortex, and there were positive correlations between the SCWC and age (ages $6-13$ years; mean $9.35 \pm 2.13$ years). The researchers concluded that prefrontal brain activation in healthy children during the Stroop color-word task is similar to that of healthy adults, measured using NIRS [51]. Similar results were obtained in the present study. In both groups, there were positive correlations between SCWC scores and age, and there were no correlations between SCWC scores and FIQ. This result was consistent with previous research on the Stroop that documented that children became progressively faster as they responded verbally to stimuli [52]. These data suggest that the Stroop color-word task used in the present study may be a useful task for children.

Several potential limitations of the present study should be taken into consideration. First, NIRS has several disadvantages compared with other modalities [53]: for example, NIRS enables measurement of $\mathrm{Hb}$ concentration changes only as relative values, not as absolute values. We used the Stroop color-word task with a clear baseline task to overcome these potential problems. In addition, we measured $\mathrm{Hb}$ concentration changes between the activation task and the baseline task, and performed the task three times to average out the potential effects of incidental changes, and prevent participants from becoming tired. The grand average waveforms of oxy- $\mathrm{Hb}$ concentration changes in the ASD group did not indicate a regional cerebral blood flow decrease during the activation task or a difference in blood flow between the baseline and activation tasks. Second, the spatial resolution for detecting hemodynamic responses from the scalp surface using NIRS is lower compared with fMRI, SPECT and PET. However, abnormal prefrontal hemodynamic responses in individuals with ASD are certainly detectible with NIRS. Third, several previous studies have shown that superficial hemodynamic changes, such as skin blood flow, can affect prefrontal NIRS hemoglobin signals $[54,55]$. Thus, the present findings could have been influenced by skin blood flow. However, Sato et al. [56] conducted simultaneous NIRS, fMRI, and laser Doppler flowmeter measurements to determine whether prefrontal NIRS hemoglobin signals reflected cortical activity rather than superficial effects. They concluded that NIRS can be used to measure hemodynamic signals originating from prefrontal cortex activation. Fourth, only male children were included in the current study. ASD is more prevalent in males, and gender differences exist in clinical manifestation, cognitive deficits, and brain dysfunctions $[32-34,57,58]$. Thus, our findings may not be generalizable to the female population. Nevertheless, the current finding of abnormal prefrontal hemodynamic responses in male children with ASD is valuable for extending current knowledge. Fifth, the sample size was small, although the 12 male children with ASD were drug-naïve and none had comorbid psychiatric, neurodevelopmental or neurological disorders. However, the required sample size was 11 when we calculated it as $\alpha$ error prob 0.05 , power (1- $\beta$ error prob) 0.8 , and effect size 1.3 (effect size in previous studies [23, 26]: 1.3 to 1.6 ) before the start of this study. In this study, effect size was 1.4 to 1.5 . This study is adequately powered (power (1- $\beta$ error prob): 0.95 to 0.97 ). Future research with larger sample sizes will be needed to confirm the current findings.

\section{Conclusion}

To our knowledge, this is the first 24-channel NIRS study examining reduced prefrontal hemodynamic responses in male children with ASD during the Stroop color-word task. We found that oxy-Hb changes in 12 drug-naive male children with ASD were significantly smaller than those in 12 healthy male children in the dorsolateral prefrontal cortex. In addition, 24-channel NIRS systems appears to be a very useful measurement modality for assessing the frontal function of ASD, as it enables non-invasive functional mapping of the cerebral cortex and has much shorter measurement times (about $5 \mathrm{~min}$ ) compared with other functional brain imaging methodologies.

\section{Abbreviations \\ ASD: autism spectrum disorder; NIRS: near-infrared spectroscopy; oxy-Hb: oxygenated hemoglobin; deoxy-Hb: deoxygenated hemoglobin; PET: positron emission tomography; FIQ: full-scale intelligence quotient; SCWC-1: Stroop color-word task number of correct answers first time; SCWC-2: Stroop color- word task number of correct answers second time; SCWC-3: Stroop color- word task number of correct answers third time; FDR: false discovery rate; fMRI: functional magnetic resonance imaging; SPECT: single-photon emission computed tomography.}

\section{Acknowledgements}

We wish to thank the participants for their involvement in the study. The authors would also like to thank the Hitachi Medical Corporation for providing the ETG-4000 equipment and skilled technical and methodical support. We thank Benjamin Knight, M.Sc., from Edanz Group (http://www.edanzediti ng.com/ac) for editing a draft of this manuscript.

\section{Authors' contributions}

$\mathrm{MU}$ was involved in the collection of the data and wrote the first draft of the manuscript. TO, Jl, KO, KY, YN, NK and TK supervised the entire project, were critically involved in the design, and contributed to the editing of the final manuscript. All authors read and approved the final manuscript. 


\section{Funding}

Not applicable.

\section{Availability of data and materials}

The dataset of this study is available from the corresponding author on reasonable request.

\section{Ethics approval and consent to participate}

This study was approved by the Institutional Review Board at the Nara Medical University (Approval Number 325-2). All participants and/or their parents provided written informed consent for their participation in the study.

\section{Consent for publication}

Not applicable.

\section{Competing interests}

The authors declare that they have no competing interests.

\section{Author details}

${ }^{1}$ Department of Psychiatry, Manyo Hospital, Kashihara, Japan. ${ }^{2}$ Department of Psychiatry, Nara Medical University, 840 Shijyo-cho, Kashihara, Nara 634-8522, Japan. ${ }^{3}$ Faculty of Nursing, Nara Medical University, Kashihara, Japan.

\section{Received: 28 October 2018 Accepted: 22 June 2019}

Published online: 28 June 2019

\section{References}

1. American Psychiatric Association. Diagnostic and statistical manual of mental disorders. 5th ed. Arlington: American Psychiatric Association; 2013.

2. Corbett BA, Constantine LJ. Autism and attention deficit hyperactivity disorder: assessing attention and response control with the integrated visual and auditory continuous performance test. Child Neuropsychol. 2006;12:335-48.

3. van der Meer JM, Oerlemans AM, van Steijn DJ, Lappenschaar MG, de Sonneville LM, Buitelaar JK, et al. Are autism spectrum disorder and attention-deficit/hyperactivity disorder different manifestations of one overarching disorder? Cognitive and symptom evidence from a clinical and population-based sample. J Am Acad Child Adolesc Psychiatry. 2012;51:1160-72

4. Schmitz N, Rubia K, Daly E, Smith A, Williams S, Murphy DG. Neural correlates of executive function in autistic spectrum disorders. Biol Psychiatry. 2006:59:7-16.

5. Shafritz KM, Dichter GS, Baranek GT, Belger A. The neural circuitry mediating shifts in behavioral response and cognitive set in autism. Biol Psychiatry. 2008;63:974-80.

6. Hughes C, Russell J, Robbins TW. Evidence for executive dysfunction in autism. Neuropsychologia. 1994;32:477-92.

7. Hill EL. Evaluating the theory of executive dysfunction in autism. Dev Rev. 2004:24:189-233.

8. Strangman G, Boas DA, Sutton JP. Non-invasive neuroimaging using nearinfrared light. Biol Psychiatry. 2002;52:679-93.

9. Boas DA, Dale AM, Franceschini MA. Diffuse optical imaging of brain activation: approaches to optimizing image sensitivity, resolution, and accuracy. Neuroimage. 2004;23(Suppl 1):S275-88.

10. Obrig H, Villringer A. Beyond the visible-imaging the human brain with light. J Cereb Blood Flow Metab. 2003;23:1-18.

11. Villringer K, Minoshima S, Hock C, Obrig H, Ziegler S, Dirnagl U, et al. Assessment of local brain activation. A simultaneous PET and near-infrared spectroscopy study. Adv Exp Med Biol. 1997;413:149-53.

12. Ohmae E, Ouchi Y, Oda M, Suzuki T, Nobesawa S, Kanno T, et al. Cerebral hemodynamics evaluation by near-infrared time-resolved spectroscopy: correlation with simultaneous positron emission tomography measurements. Neuroimage. 2006;29:697-705.

13. Matsuo K, Kato T, Taneichi K, Matsumoto A, Ohtani T, Hamamoto T, et al. Activation of the prefrontal cortex to trauma-related stimuli measured by near-infrared spectroscopy in posttraumatic stress disorder due to terrorism. Psychophysiology. 2003;40:492-500.

14. Suto T, Fukuda M, Ito M, Uehara T, Mikuni M. Multichannel near-infrared spectroscopy in depression and schizophrenia: cognitive brain activation study. Biol Psychiatry. 2004;55:501-11.

15. Kameyama M, Fukuda M, Yamagishi Y, Sato T, Uehara T, Ito M, et al. Frontal lobe function in bipolar disorder: a multichannel near-infrared spectroscopy study. Neuroimage. 2006;29:172-84.

16. Kubota Y, Toichi M, Shimizu M, Mason RA, Coconcea CM, Findling RL, et al. Prefrontal activation during verbal fluency tests in schizophrenia-a near-infrared spectroscopy (NIRS) study. Schizophr Res. 2005;77:65-73.

17. Shinba T, Nagano M, Kariya N, Ogawa K, Shinozaki T, Shimosato S, et al. Near-infrared spectroscopy analysis of frontal lobe dysfunction in schizophrenia. Biol Psychiatry. 2004;55:154-64

18. Fallgatter AJ, Roesler M, Sitzmann L, Heidrich A, Mueller TJ, Strik WK. Loss of functional hemispheric asymmetry in Alzheimer's dementia assessed with near-infrared spectroscopy. Brain Res Cogn Brain Res. 1997;6:67-72.

19. Hock C, Villringer K, Müller-Spahn F, Wenzel R, Heekeren H, Schuh-Hofer $\mathrm{S}$, et al. Decrease in parietal cerebral hemoglobin oxygenation during performance of a verbal fluency task in patients with Alzheimer's disease monitored by means of near-infrared spectroscopy (NIRS)-correlation with simultaneous rCBF-PET measurements. Brain Res. 1997;755:293-303.

20. Kuwabara H, Kasai K, Takizawa R, Kawakubo Y, Yamasue H, Rogers MA, et al. Decreased prefrontal activation during letter fluency task in adults with pervasive developmental disorders: a near-infrared spectroscopy study. Behav Brain Res. 2006;172:272-7.

21. Ehlis AC, Bähne CG, Jacob CP, Herrmann MJ, Fallgatter AJ. Reduced lateral prefrontal activation in adult patients with attention-deficit/hyperactivity disorder (ADHD) during a working memory task: a functional near-infrared spectroscopy (fNIRS) study. J Psychiatr Res. 2008;42:1060-7.

22. Okada K, Ota T, lida J, Kishimoto N, Kishimoto T. Lower prefrontal activity in adults with obsessive-compulsive disorder as measured by nearinfrared spectroscopy. Prog Neuropsychopharmacol Biol Psychiatry. 2013:43:7-13.

23. Ota T, lida J, Sawada M, Suehiro Y, Yamamuro K, Matsuura H, et al. Reduced prefrontal hemodynamic response in pediatric obsessivecompulsive disorder as measured by near-infrared spectroscopy. Child Psychiatry Hum Dev. 2013:44:265-77.

24. Weber $\mathrm{P}$, Lütschg J, Fahnenstich $\mathrm{H}$. Cerebral hemodynamic changes in response to an executive function task in children with attention-deficit hyperactivity disorder measured by near-infrared spectroscopy. J Dev Behav Pediatr. 2005;26:105-11.

25. Inoue Y, Sakihara K, Gunji A, Ozawa H, Kimiya S, Shinoda H, et al. Reduced prefrontal hemodynamic response in children with ADHD during the Go/ NoGo task: a NIRS study. Neuro Report. 2012;23:55-60.

26. Negoro H, Sawada M, lida J, Ota T, Tanaka S, Kishimoto T. Prefrontal dysfunction in attention-deficit/hyperactivity disorder as measured by near-infrared spectroscopy. Child Psychiatry Hum Dev. 2010;41:193-203.

27. Yamamuro K, Ota T, lida J, Nakanishi Y, Uratani M, Matsuura H, et al. Prefrontal dysfunction in pediatric Tourette's disorder as measured by near-infrared spectroscopy. BMC Psychiatry. 2015;15:102.

28. Kita Y, Gunji A, Inoue Y, Goto T, Sakihara K, Kaga M, et al. Self-face recognition in children with autism spectrum disorders: a near-infrared spectroscopy study. Brain Dev. 2011;33:494-503.

29. Funabiki Y, Murai T, Toichi M. Cortical activation during attention to sound in autism spectrum disorders. Res Dev Disabil. 2012;33:518-24.

30. Yasumura A, Kokubo N, Yamamoto H, Yasumura Y, Nakagawa E, Kaga $M$, et al. Neurobehavioral and hemodynamic evaluation of Stroop and reverse Stroop interference in children with attention-deficit/hyperactivity disorder. Brain Dev. 2014;36:97-106.

31. Xiao T, Xiao Z, Ke X, Hong S, Yang H, Su Y, et al. Response inhibition impairment in high functioning autism and attention deficit hyperactivity disorder: evidence from near-infrared spectroscopy data. PLOS ONE. 2012; 7:e46569.

32. Koyama T, Kamio Y, Inada N, Kurita H. Sex differences in WISC-III profiles of children with high-functioning pervasive developmental disorders. J Autism Dev Disord. 2009;39:135-41.

33. Bölte S, Duketis E, Poustka F, Holtmann M. Sex differences in cognitive domains and their clinical correlates in higher-functioning autism spectrum disorders. Autism. 2011;15:497-511. 
34. Lemon JM, Gargaro B, Enticott PG, Rinehart NJ. Executive functioning in autism spectrum disorders: a gender comparison of response inhibition. J Autism Dev Disord. 2011:41:352-6.

35. Kurita H, Koyama T, Inoue K. Reliability and validity of the pervasive developmental disorders assessment system. Psychiatry Clin Neurosci. 2008;62:226-33.

36. Golden CJ. A group version of the Stroop color and word test. J Pers Assess. 1975;39:386-8.

37. Laird AR, McMillan KM, Lancaster JL, Kochunov P, Turkeltaub PE, Pardo JV, et al. A comparison of label-based review and ALE meta-analysis in the Stroop task. Hum Brain Mapp. 2005;25:6-21.

38. Hoshi Y, Kobayashi N, Tamura M. Interpretation of near-infrared spectroscopy signals: a study with a newly developed perfused rat brain model. J Appl Physiol. 2001;90:1657-62.

39. Cope M, Delpy DT, Reynolds EO, Wray S, Wyatt J, van der Zee P. Methods of quantitating cerebral near infrared spectroscopy data. Adv Exp Med Biol. 1988;222:183-9.

40. Maki A, Yamashita Y, Ito Y, Watanabe E, Mayanagi Y, Koizumi H. Spatial and temporal analysis of human motor activity using non-invasive NIR topography. Med Phys. 1995;22:1997-2005.

41. Toronov V, Webb A, Choi JH, Wolf M, Michalos A, Gratton E, et al. Investigation of human brain hemodynamics by simultaneous near-infrared spectroscopy and functional magnetic resonance imaging. Med Phys. 2001:28:521-7.

42. Singh AK, Dan I. Exploring the false discovery rate in multichannel NIRS. Neuroimage. 2006;33:542-9.

43. Sasaki M. SPECT findings in autism spectrum disorders and medically refractory seizures. Epilepsy Behav. 2015;47:167-71.

44. Chantiluke K, Barrett N, Giampietro V, Santosh P, Brammer M, Simmons $A$, et al. Inverse fluoxetine effects on inhibitory brain activation in non-comorbid boys with ADHD and with ASD. Psychopharmacology. 2015;232:2071-82.

45. Shafritz KM, Bregman JD, Ikuta T, Szeszko PR. Neural systems mediating decision-making and response inhibition for social and nonsocial stimul in autism. Prog Neuropsychopharmacol Biol Psychiatry. 2015:60:112-20.

46. Kana RK, Keller TA, Minshew NJ, Just MA. Inhibitory control in high-functioning autism: decreased activation and underconnectivity in inhibition networks. Biol Psychiatry. 2007;62:198-206.

47. SilkTJ, Rinehart N, Bradshaw JL, Tonge B, Egan G, O'Boyle MW, et al. Visuospatial processing and the function of prefrontal-parietal networks in autism spectrum disorders: a functional MRI study. Am J Psychiatry. 2006:163:1440-3.
48. Christakou A, Murphy CM, Chantiluke K, Cubillo Al, Smith AB, Giampietro $\checkmark$, et al. Disorder-specific functional abnormalities during sustained attention in youth with attention deficit hyperactivity disorder (ADHD) and with autism. Mol Psychiatry. 2013;18:236-44.

49. Di Martino A, Ross K, Uddin LQ, Sklar AB, Castellanos FX, Milham MP. Functional brain correlates of social and nonsocial processes in autism spectrum disorders: an activation likelihood estimation meta-analysis. Biol Psychiatry. 2009;65:63-74.

50. Stigler KA, McDonald BC, Anand A, Saykin AJ, McDougle CJ. Structural and functional magnetic resonance imaging of autism spectrum disorders. Brain Res. 2011;1380:146-61.

51. Schroeter ML, Zysset S, Kupka T, Kruggel F, YvesCramon D. Near-infrared spectroscopy can detect brain activity during a color-word matching Stroop task in an event-related design. Hum Brain Mapp. 2002;17:61-71.

52. Schiller PH. Developmental study of color-word interference. J Exp Psychol. 1966;72:105-8.

53. Yamashita Y, Maki A, Koizumi H. Near-infrared topographic measurement system: imaging of absorbers localized in a scattering medium. Rev Sci Instrum. 1996;67:730-2.

54. Takahashi T, Takikawa Y, Kawagoe R, Shibuya S, Iwano T, Kitazawa S. Influence of skin blood flow on near-infrared spectroscopy signals measured on the forehead during a verbal fluency task. Neuroimage. 2011;57:991-1002.

55. Kirilina E, Jelzow A, Heine A, Niessing M, Wabnitz $H$, Brühl R, et al. The physiological origin of task-evoked systemic artefacts in functional near infrared spectroscopy. Neuroimage. 2012;61:70-81.

56. Sato H, Yahata N, Funane T, Takizawa R, Katura T, Atsumori H, et al. A NIRSfMRI investigation of prefrontal cortex activity during a working memory task. Neuroimage. 2013;83:158-73.

57. Rutherford M, McKenzie K, Johnson T, Catchpole C, O'Hare A, McClure I, et al. Gender ratio in a clinical population sample, age of diagnosis and duration of assessment in children and adults with autism spectrum disorder. Autism. 2016;20:628-34.

58. Loomes R, Hull L, Mandy WPL. What is the male-to-female ratio in autism spectrum disorder? A systematic review and meta-analysis. J Am Acad Child Adolesc Psychiatry. 2017;56:466-74.

\section{Publisher's Note}

Springer Nature remains neutral with regard to jurisdictional claims in published maps and institutional affiliations.
Ready to submit your research? Choose BMC and benefit from:

- fast, convenient online submission

- thorough peer review by experienced researchers in your field

- rapid publication on acceptance

- support for research data, including large and complex data types

- gold Open Access which fosters wider collaboration and increased citations

- maximum visibility for your research: over $100 \mathrm{M}$ website views per year

At BMC, research is always in progress.

Learn more biomedcentral.com/submissions 